\title{
Mucilaginibacter polysacchareus sp. nov., an exopolysaccharide-producing bacterial species isolated from the rhizoplane of the herb Angelica sinensis
}

Correspondence Kyung-Sook Whang kswhang@mokwon.ac.kr

\author{
Song-lh Han, ${ }^{1}$ Hyo-Jin Lee, ${ }^{1}$ Hae-Ran Lee, ${ }^{1}$ Ki-Kwang Kim ${ }^{1}$ \\ and Kyung-Sook Whang ${ }^{1,2}$
}

\author{
${ }^{1}$ Department of Microbial and Nanomaterials, Mokwon University, 800, Doan-dong, Seo-gu, \\ Daejeon, Republic of Korea \\ ${ }^{2}$ Institute of Microbial Ecology and Resources, Mokwon University, 800, Doan-dong, Seo-gu, \\ Daejeon, Republic of Korea
}

\begin{abstract}
Three exopolysaccharide-producing bacteria, designated strains DRP28 ${ }^{\top}$, DRP29 and DRP31, were isolated from the rhizoplane of Angelica sinensis from the Geumsan, Republic of Korea. Cells were straight rods, Gram reaction-negative, aerobic, non-motile, and catalase- and oxidasepositive. Flexirubin-type pigments were absent. Phylogenetic analysis of the 16S rRNA gene indicated that these bacteria belong to the genus Mucilaginibacter in the phylum Bacteroidetes. 16S rRNA gene sequence similarities to strains of recognized species of the genus Mucilaginibacter were 93.8-97.4\%. The major fatty acids were iso- $\mathrm{C}_{15: 0}$ and summed feature 3 $\left(\mathrm{C}_{16: 1} \omega 7 \mathrm{c}\right.$ and/or iso- $\left.\mathrm{C}_{15: 0} 2-\mathrm{OH}\right)$. The strains contained $\mathrm{MK}-7$ as the major isoprenoid quinone. Strains DRP28 ${ }^{\top}$, DRP29 and DRP31 formed a single, distinct genomospecies with DNA G $+C$ contents of 41.9-42.7 mol\% and DNA hybridization values of $82.6-86.8 \%$; the strains exhibited DNA-DNA hybridization values of only $20.4-41.3 \%$ with related species of the genus Mucilaginibacter. On the basis of evidence presented in this study, strains DRP28 ${ }^{\top}, \mathrm{DRP} 29$ and DRP31 were considered to represent a novel species of the genus Mucilaginibacter, for which the name Mucilaginibacter polysacchareus sp. nov. is proposed. The type strain is DRP28 ${ }^{\top}$ $\left(=\right.$ KACC $15075^{\top}=$ NBRC $\left.107757^{\top}\right)$.
\end{abstract}

The genus Mucilaginibacter, a member of the family Sphingobacteriaceae (Steyn et al., 1998; Pankratov et al., 2007) and the phylum Bacteroidetes, includes Gramnegative, non-motile rods that are facultatively anaerobic and produce large amounts of extracellular polysaccharide (EPS). At the time of writing, the genus Mucilaginibacter comprises at least 16 species with validly published names: Mucilaginibacter paludis and M. gracilis (Pankratov et al., 2007), M. kameinonensis (Urai et al., 2008), M. daejeonensis (An et al., 2009), M. ximonensis (Luo et al., 2009), M. oryzae (Jeon et al., 2009), M. rigui (Baik et al., 2010), M. gossypii and M. gossypiicola (Madhaiyan et al., 2010), M. angelicae (Kim et al., 2012), M. lappiensis and M. mallensis (Männistö et al., 2010), M. frigoritolerans (Männistö et al., 2010), M.

Abbreviation: EPS, extracellular polysaccharide.

The GenBank/EMBL/DDBJ accession number for the 16S rRNA gene sequence of strains DRP28 ${ }^{\top}$, DRP29 and DRP31 are HM748604, HM748605 and HQ396159, respectively.

Three supplementary figures are available with the online version of this paper. boryungensis (Kang et al., 2011), M. myungsuensis (Joung \& Joh, 2011) and M. dorajii (Kim et al., 2010). In this study, we characterized the EPS-producing bacterial strains DRP $28^{\mathrm{T}}$, DRP29 and DRP31 that were isolated from the rhizoplane of Angelica sinensis. Based on phenotypic, phylogenetic and genotypic characteristics, we suggest that these strains represent a novel species of the genus Mucilaginibacter.

Strains DRP28 ${ }^{\mathrm{T}}$, DRP29 and DRP31 were isolated from the rhizoplane of Angelica sinensis collected from the Geumsan, Republic of Korea, using the standard dilution plating technique. All isolates produced slime indicative of EPS around the colonies when grown on potato dextrose agar (PDA; Difco) medium at $25{ }^{\circ} \mathrm{C}$ for 3 days. The isolates were routinely cultured on R2A (Difco) agar medium and preserved at $-80{ }^{\circ} \mathrm{C}$ as a suspension in distilled water containing $20 \%$ glycerol (w/v).

Cells of strains DRP28 ${ }^{\mathrm{T}}$, DRP29 and DRP31 incubated on R2A medium for 3 days at $25{ }^{\circ} \mathrm{C}$ were used for physiological and biochemical tests. Cell morphology and motility was observed by phase-contrast microscopy (Nikon Eclipse 80i). 
The $\mathrm{pH}$ range for growth was determined on $\mathrm{R} 2 \mathrm{~A}$ agar. Medium sterilized by autoclaving was adjusted to $\mathrm{pH} 4-11$ (in increments of $1 \mathrm{pH}$ unit) by addition of $\mathrm{HCl}$ or $\mathrm{NaOH}$. Growth temperature $\left(4,10,15,20,25,30,37,40\right.$ and $\left.42{ }^{\circ} \mathrm{C}\right)$ and $\mathrm{NaCl}$ tolerance $(0,1,2,3,5$ and $10 \%, \mathrm{w} / \mathrm{v})$ were tested on R2A agar. Catalase and oxidase activities were determined using 3\% (v/v) hydrogen peroxide and Kovacs' reagent (Kovacs, 1956), respectively. The presence of flexirubin-type pigments was investigated as described by Reichenbach (1989). Other physiological and biochemical tests were performed using API 20E, API 20NE and API 50CH kits (bioMérieux). Enzymic activities were tested using the API ZYM kit (bioMérieux) following the manufacturer's instructions.

Colonies of strains DRP28 $8^{\mathrm{T}}$, DRP29 and DRP31 were pale pink (Supplementary Fig. S1, available in IJSEM Online). Cells of these strains were Gram-negative, non-sporeforming, non-motile rods that occurred singly, in pairs or in short chains. Strains DRP28 ${ }^{\mathrm{T}}$, DRP29 and DRP31 grew in the range $\mathrm{pH} 4-11$, with an optimum at $\mathrm{pH}$ 6.0-7.0. The temperature range for growth was $4-28{ }^{\circ} \mathrm{C}$, with an optimum at $25{ }^{\circ} \mathrm{C}$. Growth was inhibited completely at $\mathrm{NaCl}$ concentrations above $1.0 \%(\mathrm{w} / \mathrm{v})$. Detailed results of colony colour, morphological, physiological and biochemical analyses are given in Table 1.

The 16S rRNA gene of each novel strain was amplified by using universal primers 27F [5'-AGAGTTTGATC(AC)TGGCTCAG-3'] and 1492R [5'-ACGG(CT)TACCTTGTT-
ACGACTT-3'] (Weisburg et al., 1991), and their nucleotide sequences were determined with an ABI prism BigDye terminator cycle sequencing ready reaction kit v.3.1 and $\mathrm{ABI}$ 3730XL capillary DNA sequencer (Applied Biosystems). The $16 \mathrm{~S}$ rRNA gene sequences were compared with available $16 \mathrm{~S}$ rRNA gene sequences from the EzTaxon server (http://www. eztaxon.org/; Chun et al., 2007) and the GenBank database using the BLAST program (http://blast.ncbi.nlm.nih.gov/ Blast.cgi). 16S rRNA gene sequences of strains DRP28 ${ }^{\mathrm{T}}$, DRP29, DRP31 and representative members of the family Sphingobacteriaceae were aligned using CLUSTAL X (Thompson et al., 1997). Phylogenetic trees were generated by three algorithms, the neighbour-joining (Saitou \& Nei, 1987), maximum-parsimony (Fitch, 1971) and maximumlikelihood (Felsenstein, 1981) methods, using the PHYLIP program package (Felsenstein, 1984, 2005). Bootstrap analysis to evaluate the stability of phylogenetic tree was achieved using a consensus tree from the neighbour-joining, maximum-parsimony and maximum-likelihood methods, based on 1000 resamplings. Probe labelling for DNA-DNA hybridization was conducted by using the non-radioactive DIG-High Prime system (Roche); hybridized DNA was visualized using the DIG luminescent detection kit (Roche). DNA-DNA relatedness was quantified by using Bio-1D image analysis software (Vilber Lourmat).

The sequences of strains DRP28 ${ }^{\mathrm{T}}, \mathrm{DRP} 29$ and DRP31 were closely related to those of members of the genus

Table 1. Differentiating phenotypic characteristics of strains $D R P 28^{\top}, D R P 29, D R P 31$ and related species of the genus Mucilaginibacter

Strains: 1, M. polysacchareus sp. nov. DRP28 $8^{\mathrm{T}} ; 2$, M. polysacchareus sp. nov. DRP29; 3, M. polysacchareus sp. nov. DRP31; 4, M. gossypii Gh-67 ${ }^{\mathrm{T}}$ (data from Madhaiyan et al., 2010); 5, M. lappiensis ANJLI2 ${ }^{\mathrm{T}}$ (Männistö et al., 2010); 6, M. gossypiicola Gh-48 ${ }^{\mathrm{T}}$ (Madhaiyan et al., 2010); 7, M. rigui

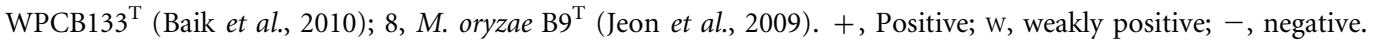

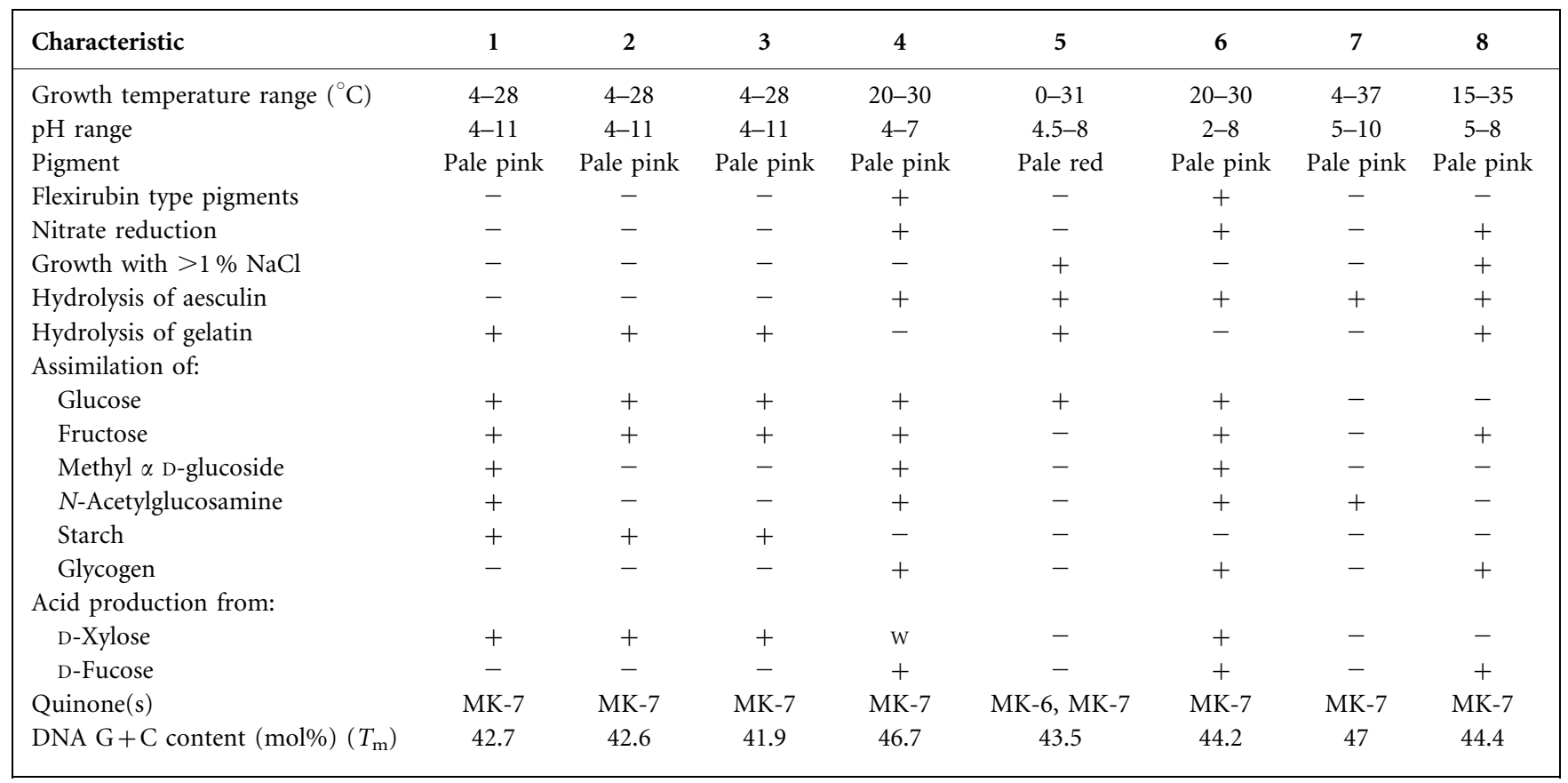




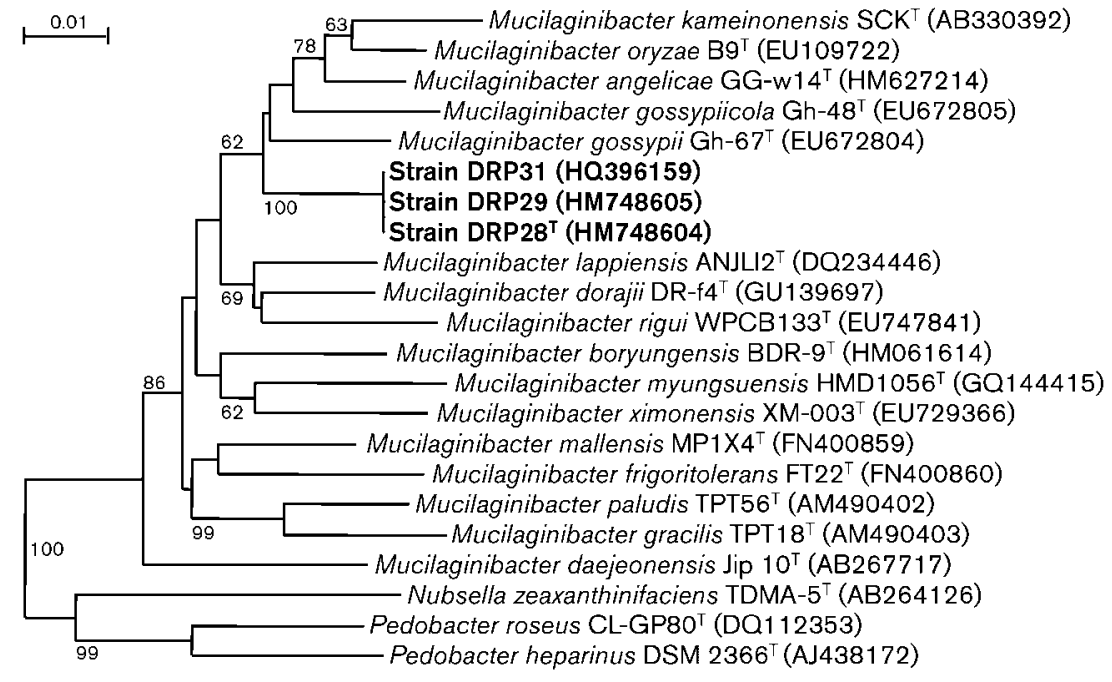

Fig. 1. Neighbour-joining phylogenetic tree based on nearly complete 16S rRNA gene sequences showing relationships between strains DRP28 ${ }^{\top}$, DRP29 and DRP31, members of the genus Mucilaginibacter and representative members of the family Sphingobacteriaceae and the phylum Bacteroidetes. Numbers at nodes are levels of percentage bootstrap support (>50\%) based on neighbour-joining analyses of 1000 resampled datasets. Bar, $0.01 \mathrm{nt}$ substitutions per position.
Mucilaginibacter but could be clearly distinguished from the type species of the genus. 16S rRNA gene sequence similarity values between strain $\mathrm{DRP} 28^{\mathrm{T}}$ and the strains representing the species Mucilaginibacter were 93.9-97.4\%. The 16S rRNA gene sequence of strain DRP $28^{\mathrm{T}}$ had 97.4, 97.2, 97 and $96 \%$ pairwise similarity, respectively, to those from M. gossypii $\mathrm{Gh}-67^{\mathrm{T}}, M$. lappiensis $\mathrm{ANJLI} 2^{\mathrm{T}}, M$. gossypiicola Gh- $48^{\mathrm{T}}$ and $M$. oryzae $\mathrm{B}^{\mathrm{T}}$. The neighbourjoining tree (Fig. 1) showed that strains DRP28 ${ }^{\mathrm{T}}$, DRP29 and DRP31 formed a monophyletic clade with the members of the genus Mucilaginibacter with $100 \%$ bootstrap support. DNA-DNA hybridization showed less than $41.3 \%$ DNA-DNA relatedness between strains DRP $28^{\mathrm{T}}$, DRP29, DRP31 and the reference strains (summarized in Table 2). The DNA G $+\mathrm{C}$ contents of strains DRP $28^{\mathrm{T}}$, DRP29 and DRP31 were 42.7, 42.6 and $41.9 \mathrm{~mol} \%$, respectively (Table 2 ).

Isoprenoid quinones were extracted with chloroform/ methanol $(2: 1, \mathrm{v} / \mathrm{v})$ and purified by TLC on Merck silica gel 60 F254 plates $(20 \times 20 \mathrm{~cm}, 0.5 \mathrm{~cm}$ thick $)$ using a mixture of petroleum benzene and diethyl ether $(85: 15, \mathrm{v} /$ v) as the solvent. Spots were scraped off and then analysed by HPLC as described by Collins \& Jones (1981). The predominant respiratory quinone is MK-7 (Table 1).

Cellular fatty acid profiles were determined for strains grown on TSA for one day at $28{ }^{\circ} \mathrm{C}$. Fatty acid methyl esters were extracted and prepared by using the standard protocol of the Microbial Identification System (MIDI, 1999). Extracted fatty acid methyl esters were separated by using a gas chromatograph (HP6890N GC; Agilent) and identified with the Microbial Identification Sherlock software package (MIDI; database TSBA 40, version 4.0). The major fatty acids of strain DRP $28^{\mathrm{T}}$ were summed feature $3\left(\mathrm{C}_{16: 1} \omega 7 c\right.$ and/or iso- $\left.\mathrm{C}_{15: 0} 2-\mathrm{OH} ; 45.45 \%\right)$ and iso- $\mathrm{C}_{15: 0}(21.32 \%)$ (Table 3$)$. Summed feature 3 and iso$\mathrm{C}_{15: 0}$ have been previously reported as the predominant, characteristic fatty acids of members of the genus Mucilaginibacter (Pankratov et al., 2007; Baik et al., 2010).

Polar lipids were analysed according to Minnikin et al. (1984). The polar lipid profile consisted of phosphatidylethanolamine, an unidentified aminophospholipid, two unidentified phospholipids, sphingoglycolipid, an unidentified aminolipid and unidentified lipids. Phosphatidylethanolamine and the unidentified aminophospholipid are major polar lipids (Supplementary Fig. S2).

Sphingoglycolipids were analysed by the method of Hirai et al. (1995). For detection of alkaline-stable glycolipids, the total extractable lipids were incubated in $1 \mathrm{M} \mathrm{KCl}$ and methanol $(2: 1, \mathrm{v} / \mathrm{v})$ for $2 \mathrm{~h}$ at $37{ }^{\circ} \mathrm{C}$ and analysed by TLC with a solvent system composed of chloroform, methanol and water $\left(70: 30: 5\right.$, by volume). Strains DRP28 ${ }^{\mathrm{T}}$, DRP29 and DRP31 contained sphingoglycolipid (Supplementary Fig. S3).

Table 2. DNA-DNA relatedness of strains DRP28 ${ }^{\top}$, DRP29, DRP31 and related type strains of the genus Mucilaginibacter

Strains: 1, M. polysacchareus sp. nov. DRP $28^{\mathrm{T}} ; 2$, M. polysacchareus sp. nov. DRP29; 3, M. polysacchareus sp. nov. DRP31; 4, M. gossypii KCTC $22380^{\mathrm{T}}$; 5, M. lappiensis LMG $25358^{\mathrm{T}}$; 6, M. gossypiicola KCTC $22379^{\mathrm{T}} ; 7$, M. oryzae KACC $12816^{\mathrm{T}}$.

\begin{tabular}{|lcccccc|}
\hline \multirow{2}{*}{ Strain } & \multicolumn{5}{c|}{ Hybridization (\%) with DNA from: } \\
\cline { 2 - 7 } & $\mathbf{1}$ & $\mathbf{2}$ & $\mathbf{3}$ & $\mathbf{4}$ & $\mathbf{5}$ & $\mathbf{6}$ \\
\hline 2 & 86.77 & & & & & \\
3 & 82.60 & 83.94 & & & & \\
4 & 41.30 & 40.80 & 40.6 & & & \\
5 & 36.43 & 29.41 & 28.73 & & & \\
6 & 20.88 & 32.58 & 39.27 & 38.20 & 37.56 & \\
7 & 20.40 & 28.40 & 31.20 & 30.50 & 32.30 & 29.10 \\
\hline
\end{tabular}


Table 3. Cellular fatty acid compositions (\%) of strains representing the genus Mucilaginibacter

Strains: 1, M. polysacchareus sp. nov. DRP28 $8^{\mathrm{T}} ; 2$, M. polysacchareus sp. nov. DRP29; 3, M. polysacchareus sp. nov. DRP31; 4, M. gossypii Gh-67 ${ }^{\mathrm{T}}$ (data from Madhaiyan et al., 2010); 5, M. lappiensis ANJLI2 ${ }^{\mathrm{T}}$ ( data from Männistö et al., 2010); 6, M. gossypiicola Gh-48 ${ }^{\mathrm{T}}$ (data from Madhaiyan et al., 2010); 7, M. rigui $\mathrm{WPCB} 33^{\mathrm{T}}$ (data from Baik et al., 2010); 8, M. oryzae $\mathrm{B}^{\mathrm{T}}$ (data from Jeon et al., 2009). Values are percentages of total fatty acids. Fatty acids representing less than $0.1 \%$ in all strains were omitted. ECL, Equivalent chain-length; tr, trace $(<0.1 \%) ;-$, not detected/not reported.

\begin{tabular}{|c|c|c|c|c|c|c|c|c|}
\hline Strain & 1 & 2 & 3 & 4 & 5 & 6 & 7 & 8 \\
\hline \multicolumn{9}{|l|}{ Saturated acids } \\
\hline $\mathrm{C}_{14: 0}$ & 1.2 & 1.55 & 0.97 & 1.2 & $\operatorname{tr}$ & 1.7 & $\operatorname{tr}$ & 1.7 \\
\hline $\mathrm{C}_{16: 0}$ & 5.79 & 10.11 & 6.01 & 15 & 3.7 & 17 & $\operatorname{tr}$ & 8.5 \\
\hline $\mathrm{C}_{17: 0}$ & - & - & - & 0.2 & - & 0.3 & - & - \\
\hline $\mathrm{C}_{18: 0}$ & - & - & - & 1.6 & - & - & - & - \\
\hline \multicolumn{9}{|l|}{ Branched chain } \\
\hline iso- $\mathrm{C}_{11: 0}$ & 0.36 & 0.49 & 0.47 & 0.2 & - & - & - & 0.1 \\
\hline iso- $\mathrm{C}_{13: 0}$ & 0.22 & 0.27 & 0.39 & 0.2 & - & - & - & - \\
\hline iso- $\mathrm{C}_{14: 0}$ & - & - & - & - & - & - & 3.3 & - \\
\hline iso- $\mathrm{C}_{15: 0}$ & 21.32 & 18.65 & 23.01 & 25.8 & 18.9 & 20.2 & 34.1 & 23.9 \\
\hline anteiso- $\mathrm{C}_{15: 0}$ & - & - & - & - & $\operatorname{tr}$ & - & 26.7 & 0.2 \\
\hline iso- $\mathrm{C}_{17: 1}$ & - & - & - & - & 2.7 & - & - & - \\
\hline iso- $\mathrm{C}_{17: 1} \omega 9 c$ & 1.14 & 0.99 & 1.16 & 1.1 & - & 0.5 & 3.4 & 1.9 \\
\hline \multicolumn{9}{|l|}{ Unsaturated acids } \\
\hline $\mathrm{C}_{15: 1} \omega 6 c$ & 0.94 & - & 0.88 & 0.7 & - & 0.6 & - & 0.4 \\
\hline $\mathrm{C}_{16: 1} \omega 5 c$ & 4.02 & 0.82 & 4.32 & 2.8 & 6.8 & 1.3 & - & 1.4 \\
\hline $\mathrm{C}_{17: 1} \omega 5 c$ & - & - & - & 1.5 & - & - & - & - \\
\hline $\mathrm{C}_{17: 1} \omega 8 c$ & 0.49 & - & - & 0.3 & - & 0.5 & - & 0.3 \\
\hline $\mathrm{C}_{18: 1} \omega 5 c$ & - & - & - & - & - & - & 1.4 & \\
\hline $\mathrm{C}_{18: 1} \omega 7 c$ & - & - & - & 0.2 & - & - & - & - \\
\hline $\mathrm{C}_{18: 1} \omega 9 c$ & - & - & - & 0.5 & - & - & - & 0.1 \\
\hline \multicolumn{9}{|l|}{ Hydroxylated } \\
\hline iso- $\mathrm{C}_{15: 0} 3-\mathrm{OH}$ & 2.12 & 3.33 & 2.19 & 1.9 & 2.2 & 4.5 & 5.9 & 2.2 \\
\hline iso- $\mathrm{C}_{16: 0} 3-\mathrm{OH}$ & - & - & - & 0.3 & - & 0.5 & 2.6 & 0.2 \\
\hline iso- $\mathrm{C}_{17: 0} 3-\mathrm{OH}$ & 3.55 & 1.69 & 3.14 & 6.5 & 14.3 & 6.1 & 5.4 & 5.4 \\
\hline \multicolumn{9}{|l|}{ Summed features ${ }^{*}$} \\
\hline 1 & - & - & - & - & - & - & 1.7 & - \\
\hline 2 & - & - & - & - & - & 0.5 & - & 0.4 \\
\hline 3 & 45.45 & 55.28 & 42.96 & 33 & 45 & 39.6 & $\operatorname{tr}$ & 43.7 \\
\hline 4 & - & - & - & 0.5 & - & 0.6 & 1.7 & - \\
\hline \multicolumn{9}{|l|}{ Unknown } \\
\hline ECL 13.565 & 2.87 & 2.14 & 4.79 & - & - & - & - & 0.7 \\
\hline ECL 14.263 & - & - & - & - & - & - & 2.2 & - \\
\hline ECL 16.582 & - & - & - & - & - & - & - & 0.3 \\
\hline
\end{tabular}

${ }^{*}$ Summed features are groups of two or three fatty acids that cannot be separated by GLC with the MIDI system. Summed feature 1 comprised $\mathrm{C}_{13: 0}$ $3-\mathrm{OH}$ and/or iso- $\mathrm{C}_{15: 1} \mathrm{H}$; summed feature 2 comprised iso- $\mathrm{C}_{16: 1} \mathrm{I}$ and/or $\mathrm{C}_{14: 0} 3-\mathrm{OH}$; summed feature 3 comprised $\mathrm{C}_{16: 1} \omega 7 c$ and/or iso- $\mathrm{C}_{15: 0} 2-$ $\mathrm{OH}$; summed feature 4 comprised anteiso- $\mathrm{C}_{17: 1} \mathrm{~B}$ and/or iso- $\mathrm{C}_{17: 1} \mathrm{I}$. 


\section{Description of Mucilaginibacter polysacchareus sp. nov.}

Mucilaginibacter polysacchareus (po.ly.sac.cha're.us. Gr. adj. polu many; Gr. n. sakchâr sugar; L. masc. suff. -eus suffix denoting made of or belonging to; N.L. masc. adj. polysacchareus with many saccharides).

Cells are Gram-reaction-negative, non-endospore-forming, non-motile, aerobic rods. Colonies on R2A agar are circular, convex with entire margins, mucoid, translucent, pale pink and approximately $3.0 \mathrm{~mm}$ in diameter after 3 days at $25{ }^{\circ} \mathrm{C}$ (pH 7). Large amounts of exopolysaccharides are produced. Growth occurs at $\mathrm{pH} 4-11$ (optimum, $\mathrm{pH}$ 6-7) and at 4-28 ${ }^{\circ} \mathrm{C}$ (optimum, $25{ }^{\circ} \mathrm{C}$ ). $\mathrm{NaCl}$ inhibits growth at concentrations above $1 \%(\mathrm{w} / \mathrm{v})$. Flexirubin-type pigments are absent. Oxidaseand catalase- positive. Positive for hydrolysis of Tween 20 and starch but negative for hydrolysis of alginate, casein, cellulose, chitin, CM-cellulose, pectin, Tween 80, L-tyrosine and xylan. Positive reactions (API 20E and 20NE systems) for $\beta$ glucosidase, protease activity, assimilation of mannose, $\mathrm{N}$ acetylglucosamine and maltose, and fermentation of glucose, arabinose, rhamnose, sucrose and melibiose. Negative reactions for arginine dihydrolase, nitrate reduction, fermentation of mannitol, and assimilation of gluconate, caprate, adipate, malate, citrate and phenylacetate. In the API 50CH system, acid is produced from D-xylose, galactose, glucose, fructose, mannose, methyl $\alpha$-D-glucoside, $N$-acetylglucosamine, amygdalin, aesculin, salicin, cellobiose, maltose, lactose, melibiose, sucrose, trehalose, melezitose, raffinose, starch, gentiobiose, turanose and L-fucose; acid is not produced from glycerol, erythritol, D-arabinose, L-arabinose, ribose, L-xylose, adonitol, methyl $\beta$-D-xylopyranoside, sorbose, rhamnose, dulcitol, inositol, mannitol, sorbitol, methyl $\alpha$-D-mannopyranoside, arbutin, inulin, glycogen, xylitol, D-lyxose, D-tagatose, D-fucose, D-arabitol, L-arabitol, gluconate, 2-ketogluconate or 5-ketogluconate. In the API ZYM gallery, alkaline phosphatase, leucine arylamidase, valine arylamidase, cystine arylamidase, trypsin, acid phosphatase, $\alpha$-galactosidase, $\beta$-galactosidase, $\alpha$-glucuronidase, $\beta$-glucosidase, $N$-acetyl- $\beta$-glucosaminidase and $\alpha$-fucosidase activities are present; but esterase (C4), esterase lipase (C8), lipase (C14), $\alpha$-chymotrypsin, naphthyl-AS-BI-phosphohydrolase, $\beta$-glucuronidase, $\alpha$-mannosidase and trypsin activities are absent. The major fatty acids are summed feature 3 and iso- $\mathrm{C}_{15: 0}$. The major cellular polar lipids are phosphatidylethanolamine and an unidentified aminophospholipid. Sphingoglycolipids are detected. The DNA G $+\mathrm{C}$ content of the type strain is $42.7 \mathrm{~mol} \%$. The only respiratory quinone detected is menaquinone 7 (MK-7).

The type strain, DRP $28^{\mathrm{T}}\left(=\mathrm{KACC} 15075^{\mathrm{T}}=\mathrm{NBRC} 107757^{\mathrm{T}}\right.$ ), was isolated from the rhizoplane of Angelica sinensis, the sample being collected from the Geumsan, located in the Republic of Korea.

\section{Acknowledgements}

This research was supported financially by the Ministry of Education, Science and Technology (MEST) and Korea Institute for Advancement of Technology (KIAT) through the Human Resource Training Project for Regional Innovation (M-02-20080704171810).

\section{References}

An, D. S., Yin, C. R., Lee, S. T. \& Cho, C. H. (2009). Mucilaginibacter daejeonensis sp. nov., isolated from dried rice straw. Int J Syst Evol Microbiol 59, 1122-1125.

Baik, K. S., Park, S. C., Kim, E. M., Lim, C. H. \& Seong, C. N. (2010). Mucilaginibacter rigui sp. nov., isolated from wetland freshwater, and emended description of the genus Mucilaginibacter. Int J Syst Evol Microbiol 60, 134-139.

Chun, J., Lee, J. H., Jung, Y., Kim, M., Kim, S., Kim, B. K. \& Lim, Y. W. (2007). EzTaxon: a web-based tool for the identification of prokaryotes based on $16 \mathrm{~S}$ ribosomal RNA gene sequences. Int J Syst Evol Microbiol 57, 2259-2261.

Collins, M. D. \& Jones, D. (1981). Distribution of isoprenoid quinone structural types in bacteria and their taxonomic implication. Microbiol Rev 45, 316-354.

Felsenstein, J. (1981). Evolutionary trees from DNA sequences: a maximum likelihood approach. J Mol Evol 17, 368-376.

Felsenstein, J. (1984). Distance methods for inferring phylogenies: a justification. Evolution 38, 16-24.

Felsenstein, J. (2005). PHYLIP (phylogeny inference package), version 3.65. Distributed by the author. Department of Genome Sciences, University of Washington, Seattle, USA.

Fitch, W. M. (1971). Toward defining the course of evolution: minimum change for a specific tree topology. Syst Zool 20, 406416.

Hirai, Y., Haque, M., Yoshida, T., Yokota, K., Yasuda, T. \& Oguma, K. (1995). Unique cholesteryl glucosides in Helicobacter pylori: composition and structural analysis. J Bacteriol 177, 5327-5333.

Jeon, Y., Lee, S.-S., Chung, B.-S., Kim, J.-M., Bae, J.-W., Park, S.-K. \& Jeon, C. O. (2009). Mucilaginibacter oryzae sp. nov., isolated from soil of a rice paddy. Int J Syst Evol Microbiol 59, 1451-1454.

Joung, Y. \& Joh, K. (2011). Mucilaginibacter myungsuensis sp. nov., isolated from a mesotrophic artificial lake. Int J Syst Evol Microbiol 61, 1506-1510.

Kang, S. J., Jung, Y. T., Oh, K. H., Oh, T. K. \& Yoon, J. H. (2011). Mucilaginibacter boryungensis sp. nov., isolated from soil. Int J Syst Evol Microbiol 61, 1549-1553.

Kim, B. C., Lee, K. H., Kim, M. N., Lee, J. \& Shin, K. S. (2010). Mucilaginibacter dorajii sp. nov., isolated from the rhizosphere of Platycodon grandiflorum. FEMS Microbiol Lett 309, 130-135.

Kim, B. C., Poo, H., Lee, K. H., Kim, M. N., Kwon, O. Y. \& Shin, K. S. (2012). Mucilaginibacter angelicae sp. nov., isolated from the rhizosphere of Angelica polymorpha Maxim. Int J Syst Evol Microbiol 62, 55-60.

Kovacs, N. (1956). Identification of Pseudomonas pyocyanea by the oxidase reaction. Nature 178, 703-704.

Luo, X., Zhang, L., Dai, J., Liu, M., Zhang, K., An, H. \& Fang, C. (2009). Mucilaginibacter ximonensis sp. nov., isolated from Tibetan soil. Int $J$ Syst Evol Microbiol 59, 1447-1450.

Madhaiyan, M., Poonguzhali, S., Lee, J. S., Senthilkumar, M., Lee, K. C. \& Sundaram, S. (2010). Mucilaginibacter gossypii sp. nov. and Mucilaginibacter gossypiicola sp. nov., plant-growth-promoting bacteria isolated from cotton rhizosphere soils. Int J Syst Evol Microbiol 60, 2451-2457.

Männistö, M. K., Tiirola, M., McConnell, J. \& Häggblom, M. M. (2010). Mucilaginibacter frigoritolerans sp. nov., Mucilaginibacter 
lappiensis sp. nov. and Mucilaginibacter mallensis sp. nov., isolated from soil and lichen samples. Int J Syst Evol Microbiol 60, 2849-2856.

MIDI (1999). Sherlock Microbial Identification System Operating Manual, version 3.0. Newark, DE: MIDI, Inc.

Minnikin, D. E., O'Donnell, A. G., Goodfellow, M., Alderson, G., Athalye, M., Schaal, A. \& Parlett, J. H. (1984). An integrated procedure for the extraction of bacterial isoprenoid quinones and polar lipids. J Microbiol Methods 2, 233-241.

Pankratov, T. A., Tindall, B. J., Liesack, W. \& Dedysh, S. N. (2007). Mucilaginibacter paludis gen. nov., sp. nov. and Mucilaginibacter gracilis sp. nov., pectin-, xylan- and laminarin-degrading members of the family Sphingobacteriaceae from acidic Sphagnum peat bog. Int J Syst Evol Microbiol 57, 2349-2354.

Reichenbach, H. (1989). Order I. Cytophagales Leadbetter 1974. In Bergey's Manual of Systematic Bacteriology, vol. 3, pp. 2011-2013. Edited by J. T. Staley, M. P. Bryant, N. Pfennig \& J. G. Holt. Baltimore: Williams \& Wilkins.
Saitou, N. \& Nei, M. (1987). The neighbor-joining method: a new method for reconstructing phylogenetic trees. Mol Biol Evol 4, 406-425.

Steyn, P. L., Segers, P., Vancanneyt, M., Sandra, P., Kersters, K. \& Joubert, J. J. (1998). Classification of heparinolytic bacteria into a new genus, Pedobacter, comprising four species: Pedobacter heparinus comb. nov., Pedobacter piscium comb. nov., Pedobacter africanus sp. nov. and Pedobacter saltans sp. nov. Proposal of the family Sphingobacteriaceae fam. nov. Int J Syst Bacteriol 48, 165-177.

Thompson, J. D., Gibson, T. J., Plewniak, F., Jeanmougin, F. \& Higgins, D. G. (1997). The CLUSTAL_X windows interface: flexible strategies for multiple sequence alignment aided by quality analysis tools. Nucleic Acids Res 25, 4876-4882.

Urai, M., Aizawa, T., Nakagawa, Y., Nakajima, M. \& Sunairi, M. (2008). Mucilaginibacter kameinonensis sp. nov., isolated from garden soil. Int J Syst Evol Microbiol 58, 2046-2050.

Weisburg, W. G., Barns, S. M., Pelletier, D. A. \& Lane, D. J. (1991). 16 S ribosomal DNA amplification for phylogenetic study. J Bacteriol 173, 697-703. 